\title{
Expatriate Performance Appraisal Management: The Use Of A 360-Degree Feedback At Nokia Telecommunications
}

\author{
Bahaudin G. Mujtaba, Nova Southeastern University, USA \\ Hallie Fisher, Nova Southeastern University, USA \\ Anne-Sophie Friis, Nova Southeastern University, USA \\ Nadine Johnson, Nova Southeastern University, USA \\ Leah Kirkwood, Nova Southeastern University, USA \\ Gerardo Flores, Nova Southeastern University, USA
}

\begin{abstract}
Performance management systems are now being used as a comprehensive human resource management tool to evaluate the performance of employees through objective setting, performance appraisal and feedback, continuous training, and career development. The focal point of this article is Nokia Telecommunications, a multinational corporation with extensive experience in sending and receiving people on foreign assignments. The paper discusses performance management systems with a focus on appraisals for expatriates. Given performance appraisal challenges for expatriates, an overview assessment (using Nokia) is offered, a problem is highlighted, and a solution is presented. From the analysis and findings, an alternative performance management system of appraisals is recommended for implementation with Nokia employees working abroad and other expatriates.
\end{abstract}

Keywords: Performance management, appraisals, expatriate appraisals, 360-degree feedback, telecommunication, and employee evaluations.

\section{INTRODUCTION TO NOKIA TELECOMMUNICATIONS}

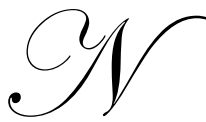

okia has been considered one of the more successful companies taking advantage of the advancements made by well-established companies, such as Motorola and other global firms. Understanding their culture and history can provide many lessons for all national and international managers who are responsible for the appraisals of expatriates.

In 1895, mining engineer Fredrik Idestam established Nokia as a forest industry enterprise in southwestern Finland. In 1898, the foundation of Finnish Rubber Works Ltd. was established and in 1912, Finnish Cable Works went into operation (Collins et al., 2006). The ownership of these two companies and Nokia gradually began to shift into the hands of just a few owners. Finally, in 1967, the three companies merged to form Nokia Corporation.

In the early 1980s, Nokia strengthened its position in the telecommunications and consumer electronics markets through the acquisitions of Mobira, Salora, Televa and Luxor of Sweden. In 1987, Nokia acquired the consumer electronics operations and part of the component business of the German Standard Elektrik Lorenz, as well as the French consumer electronics company, Oceanic. In 1987, Nokia purchased the Swiss cable machinery company, Maillefer. In the late 1980s, Nokia became the largest Scandinavian information technology company through the acquisition of Ericsson's data systems division. In 1989, Nokia conducted a significant expansion of its cable industry into continental Europe by acquiring the Dutch cable company, NKF. In 1987, the company experienced a technological breakthrough and a change in political climate to create the wire-free world that people are increasingly demanding. The political goal was set to adopt GSM throughout Europe on July 1, 1991. Finland met the deadline, thanks to Nokia and the operators. 
Politics and technology have continued to shape the industry. The 1980s and 1990s saw widespread deregulation, which stimulated competition and customer expectations. Nokia changed too, and in 1992, Jorma Ollila, then President of Nokia Mobile Phones, was appointed to head the entire Nokia Group. The corporation divested the non-core operations and focused on telecommunications in the digital age.

From 2001 and into the future, Nokia has been looking to bind its experience in mobility and networks to generate a startling vision of the future. Meeting rooms, offices and homes will be 'smart' enough to recognize their human visitors and give them whatever they want by listening to their requests. Nokia has an organizational culture that welcomes change and improvement and they usually embrace new ideas at great speed. Since the beginning of the 1990's, Nokia has concentrated on its core business - telecommunications - by divesting its information technology and basic industry operations. The result is that Nokia has greatly benefited from the strategy of concentrating on their core business (Nokia, 2008) as can be seen in Figure 1 and Table 1 .

Figure 1 - Nokia's Sales and Profits Figures (Nokia, 2008)

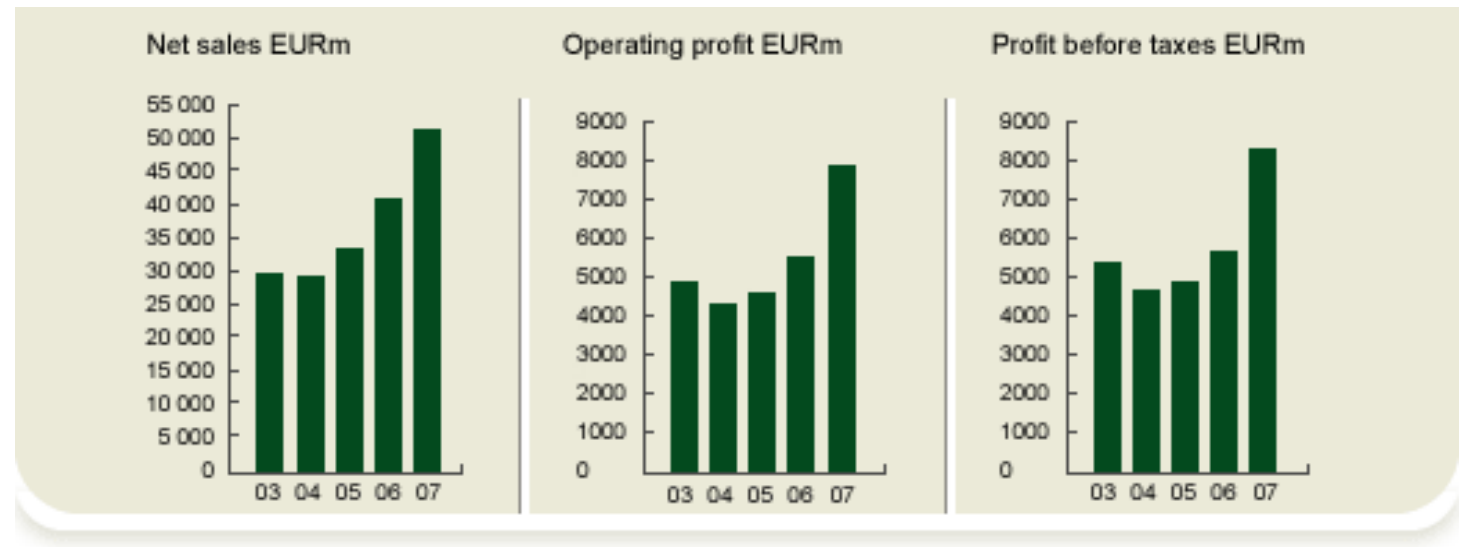

Table 1 - Nokia's Sales for 2007 and 2006 (Nokia, 2008)

\begin{tabular}{|c|c|c|c|c|}
\hline & $\begin{array}{c}2007 \\
\text { EURm }\end{array}$ & $\begin{array}{c}2006 \\
\text { EURm }\end{array}$ & Change \% & $\begin{array}{c}2005 \\
\text { EURm }\end{array}$ \\
\hline Net sales & 51058 & 41121 & 24 & 34191 \\
\hline Operating profit & 7985 & 5488 & 46 & 4639 \\
\hline Profit before taxes & 8268 & 5723 & 44 & 4971 \\
\hline Net profit & 7205 & 4306 & 67 & 3616 \\
\hline Research and development & 5647 & 3897 & 45 & 3825 \\
\hline
\end{tabular}

Nokia's people policies are given as the key reason for their reaching and maintaining a 40 percent share of the global handset market and industry-leading profit margins of 20 to 25 percent amidst competition from Asian manufacturers (Collins et al., 2006; Pollitt, 2004). Nokia's people policy, called Nokia Employee Value Proposition is broken into the following four elements used to motivate and engage the employees:

1. The Nokia way and values;

2. Performance-based rewards;

3. Professional and personal growth; and

4. Work-life balance 
Nokia describes their Employee Value Proposition policy as "a concrete employment offering for each employee from the very first Nokia day onwards." Pollitt (2004) explains that the four elements are implemented to engage and motivate the employee and maintain his or her satisfaction and well-being at work.

The first of the four elements, the Nokia way and values, is used to emphasize the importance of customer satisfaction, respect, achievement, renewal, management and leadership, and employee participation. Respect is with regard to treating not only colleagues with trust and dignity, but also customers, business partners, and the environment and community. Nokia focuses on recognizing and celebrating individual and shared successes and encouraging employee participation. To further encourage employee participation, Nokia has established the annual globally conducted "Listening to You" employee survey and "Ask HR" feedback channel on the company's humanresources intranet. There, employees can comment or ask questions about Nokia's people practices and processes and receive a prompt published response (Pollitt, p. 31).

The second of the four elements, Performance-based rewards, deals with Nokia's total-compensation package, which is customized for each country and usually consists of factors such as annual base salary, bonuses, incentives, possible participation in equity-plan and other local benefits. Pollitt goes on to explain that Nokia's total compensation is based on a pay-for-performance philosophy, with consistent performance and proven, relevant competencies rewarded.

The third of the four elements, Professional and personal growth, focuses on Nokia's policy of encouraging employees to create their own development plans, take part in on-the-job learning, and take advantage of the various courses and other learning opportunities that are available (Pollitt, p.31). Nokia understands the importance of coaching as a learning tool and believes that receiving coaching and taking part in different teams helps to foster employees' development and allows them the opportunity to share ideas and goals with both innovators and industry leaders. Nokia offers a consistent standard of training through its global network of learning centers, including online courses and a full suite of training programs for new and experienced managers. Employees are encouraged to rotate jobs within the company and, as such, all Nokia vacancies, with the exception of top senior positions, are advertised internally. Pollitt explains how the innovative performance-management system utilized by Nokia, named Investing in People (IIP), is closely aligned to the company's strategy and planning process as it involves formalized discussions between employees and their managers.

Nokia's fourth element to the Nokia Employee Value Proposition equation is work-life balance. In order to encourage employees to maintain a healthy work-life balance, Nokia offers various services that reflect their employees' changing needs and circumstances. While the various offerings may differ depending on local needs, legislation, employment market, and common practices, Pollitt points out that they usually include options, such as teleworking, mobile working, flexible working hours, sabbaticals, study leave, health-care services, and recreational activities.

Nokia's strategy for success with regard to their human resource policy has numerous practical and realworld implications. Fostering high employee morale by rewarding employee performance in a timely manner, encouraging professional and personal growth, and providing the tools for a healthy work-life balance can only help to boost the success of a company as a whole. Oftentimes, it is said that a company is only as good as the employees working for it. It only makes sense, then, to invest in one's employees' continuous education and to encourage employee participation. Considering the success that Nokia has had, not only with its employees but also within the global market, other companies would be wise to take note and implement many of the policies, including their appraisal system, which has contributed to Nokia's No. 1 slot in market share and profit margins.

\section{PERFORMANCE EVALUATIONS AND EXPATS AT NOKIA}

Leaders and managers know that employee evaluations and appraisals are usually an integral part of the comprehensive performance management program at large multinational firms. They also should know that formal and informal performance appraisals have played an important role in the effective management of private and public institutions; and its various elements must be linked to the department's mission, vision, and values if the performance management program is to be successful. For most companies, the various elements of a formal 
performance appraisal system can include selecting job performance indicators (JPI), creating criteria for measuring the success of these performance indicators (or JPIs), discussing these indicators with the employees performing these jobs, and continuously monitoring and enhancing performance by providing timely feedback to the person performing the tasks. So, the feedback process and effective communication for the manager and his/her employees become very important in the performance appraisal process.

Leaders and managers of modern organizations should know that their personal and professional success depends on their ability to qualitatively manage performance of the entire human resources in the company. As a matter-of-fact, Ashford Chea (2008) writes, "Studies have shown that highly effective people (HEP) are aware of the qualities that contribute to their success and credibility" (2008). Highly effective managers and leaders need to manage their own performance, as well as the work and productivity of their employees, peers, and suppliers. Effective leadership and management begins with successful self-leadership and, due to the inevitable workplace interdependencies, it must extend to one's immediate employees and peers.

Twenty-first century organizations and their leaders must understand and realize that their most important asset in achieving long-term success is not necessarily their technologies, but this competitive edge and the key to success lies in their people (Mujtaba, 2008). This is why continuous performance assessment, coaching and developing of each employee in the organization is so critical in today's competitive workplace. Performance assessment and developing people are important elements of a holistic paradigm for the growth and development of organizations through effective performance management systems. Herman Aguinis defined performance management as the "continuous process of identifying, measuring, and developing the performance of individuals and teams and aligning performance with the strategic goals of the organization" (2007). This definition emphasizes that an effective performance management program requires continuous feedback and improvement processes for the development of people. Aguinis states that "A system that involves employee evaluations once a year, without an ongoing effort to provide feedback and coaching so that performance can be improved, is not a true performance management system" (2007).

Today's leaders and managers know that professionals working for foreign firms and working abroad (as expatriates or expats) are realities of the modern workplace. The complex and ever-changing world of international management requires not only cultural awareness and sensitivity on the part of these expats, but also the ability to change, develop, and improve their on-the-job performance on a regular basis. As such, this provides an opportunity and puts the obligation on the shoulders of human resource professionals to continuously prepare, develop, and enable employees for working in foreign countries.

Although expatriate cultural training is now widely accepted and used, there has been very little attention devoted to evaluating this training's effectiveness and better fitting expatriate managers to the local culture to make them more effective once on the job. This case provides an example about the status of expatriate training and the need to evaluate the transfer of this training to Nokia expatriate managers on-the-job in a foreign culture. A 360degree feedback system is proposed as both a way to evaluate expatriate cultural training at the behavioral and performance levels, as well as a way to develop expatriates to make them more effective once in the local culture. A proposed expatriate management effectiveness questionnaire (EMEQ) is described in terms of its theoretical foundation and specific scales and how it could be used in a multisource feedback program for the effective development of expatriate managers.

Nokia Telecommunications is a multinational corporation with over 15 years of experience in sending and receiving employees on foreign assignments (Mendenhall, Oddou \& Stahl, 2007, p. 174). Having had this experience, one would believe that Nokia has perfected the manner in which international expatriates are evaluated. This case illustrates the lack of consistency in performance management (PM) evaluations within the following five expatriate groups at Nokia: top managers, middle managers, business establishers, customer project employees, and Research and Development (R \& D) personnel. 


\section{MANAGERS AT NOKIA TELECOMMUNICATIONS}

Within Nokia, top manager expatriates typically hold highly independent senior level positions. Their performance is managed by supervisors who are located in another country, usually at corporate or regional headquarters (Mendenhall, Oddou \& Stahl, 2007, p. 176). In these positions managers create their own performance goals which are considered very broad. The linkage between incentives objectives and performance goals at this level are very clear for the expatriate. For instance, managers may be given a certain target level to achieve operating profit.

Performance Management Evaluations for expatriates at this level are conducted by a supervisor located in another country, although this is considered by some to be biased, many of the expatriates did not consider it to be a problem. Instead the expatriates are concerned about the distance of their immediate supervisors and believe that the transition would be smoother if their supervisors were more geographically close to answer questions when issues arise regarding the foreign location. In performance management discussions with managers, the expatriates within the high organizational levels would cover developmental and longer-term matters, such as career planning. Seldom is there a discussion regarding additional training. If there is a need, expatriates in these positions would communicate these needs to their managers (Mendenhall et al., p. 176).

Middle manager expatriates within the company are also assigned co-located supervisors in their host country and some report to one or more supervisors at the headquarters in Finland. Performance management goals at this level are established between the employee and the supervisor once the expatriate arrives in the host country. Goals at this level vary from very specific to fairly specific in addition to being qualitative and quantitatively measurable. An example of a goal given to an expatriate at this level would be to collect accounts receivable within 60 days.

Every expatriate in the middle manager group works under an incentive scheme. Being that the incentives for middle manager expatriates are considered "the next higher level goals," the linkage between PM goals and incentive objectives are not always as clear-cut as they are for the top management expatriates. At time, this makes it challenging to distinguish between the expatriate's personal performance and their achievement objectives. Therefore, host country managers determine how much the financial reward would be for the expatriate and together the manager and expatriate to develop a plan for the expatriate regarding future training that could be taken on location and long-term development within the company (Mendenhall, Oddou \& Stahl, p. 177).

Performance management evaluations for these employees are formally conducted by the host country manager. Prior to the evaluation, if the expatriate reported to another supervisor in the home location, the host manager would also discuss the expatriate's performance with that supervisor to gain feedback.

\section{BUSINESS ESTABLISHER EXPATRIATES}

Expatriates in the business establisher sector of the company are generally responsible for profit and loss, as well as for creating new business ventures in foreign countries. These businesses could range from turnkey operations or green-field sites to marketing in a new geographical area. Some business establisher expatriates have a primary manager in their home location, and those who are assigned specialized functions such as finance, human resources, marketing, and accounting, would typically have a superior co-located in the host country (Mendenhall et al., p. 177).

Although training plans are agreed upon in the superior-subordinate discussions, due to time constraints, most business establishers do not participate in training activities and they work with very few performance goals. In addition, most business establishers operate within an incentive plan, but the linkage between the focused performance goals and incentive objectives are frequently unclear (Mendenhal et al., pp. 177-178). 


\section{CUSTOMER PROJECT EXPATRIATES}

Customer project expatriates are given the assignment of working on rigorous projects for current customers that could last anywhere from a few months to several years. There are three project phases that the employees are to complete: network planning, implementation and operation and maintenance. Although it is perceived that the largest number of employees and expatriates needed on a project is during the implementation phase, the number of employees working for one customer varies, depending on the phase of the project, as well as its size and scope (Mendenhall et al., p. 178).

One primary difference between the customer project expatriate and the previous three groups would be that the customer project expatriates do not agree upon any job-related goals prior to the assignment. Contingent on the manager and scope of the project, these expatriates receive information about performance expectations on a day-to-day basis from the project manager, stakeholders and/or team members. If information is not available via any of the avenues mentioned, the expatriate must rely on a formal job description in which minimum trust is placed in the value of this information by the expatriate (Mendenhall et al., p. 178).

Performance management evaluations, both formal and informal, are practically nonexistent within the customer project sector, and many of the expatriates believe that they do not receive adequate continual feedback. As an alternative, it is a customary practice that these expatriates receive a yearly bonus that encompasses both onthe-job performance, as well as the large number of extra hours that project expatriates put into completing the assignment. As mentioned by Mendenhall, Oddou and Stahl, prior to departure, expatriates extensively discuss performance management focused training and development issues with their home-based administrative managers, not the on-site project managers in the host country (2007, pp. 178-179).

\section{RESEARCH AND DEVELOPMENT PROJECT EXPATRIATES}

One distinct difference between the research and development (R\&D) project expatriates is that the R\&D employees are physically proximal to their managers. As a result, there is ongoing feedback regarding R\&D projects and daily performance management tasks are easier to complete. Also, because these are internal assignments, there is less contact with customers making it feasible for these assignments to be well planned and executed (Mendenhall et al., p. 179).

Performance goals for these expatriates are usually set by the manager in the host location, varying from vague to specific and performance evaluations at this level are generally conducted by a manager at the host location. Training and development during the international assignment is very rare due to the expatriate's lack of knowledge about available training in the host country, the superior's inability to guide the expatriate's development, expatriates may possess more experience than their managers, and because certain R\&D assignments were considered personal development. With regard to performance pay, these expatriates are entitled to bonuses that are linked to their individual performance (Mendenhall, Oddou \& Stahl, pp. 180-181).

\section{IMPROVEMENT OPPORTUNITIES AND GROWING PAINS}

Nokia has proven that structure could be obtained in a more effective manner by implementing the guidelines for the multinational company. Now the company must ensure that the guidelines are clear and concise in every level of the organization.

Within Nokia Telecommunication, the apparent challenges and problems involve the inconsistency within the International PM area. There are five groups outlined, each having its own standard and functionality in regard to goal setting, performance evaluation, training and development, and performance related pay.

Nokia Telecommunications is Finland's darling company that put them in the forefront of the telecommunications business. Nokia broke into the global market running at high rate of speed without looking beyond. Nokia Telecommunications faces many human resources challenges which include performance management of its employees around the world. In a recent study of performance management, Nokia 
Telecommunications was the entity solely studied on this subject matter. The study identified five main expatiate groups working abroad for Nokia:

1. Top managers

2. Middle Managers

3. Business Establishers

4. Customer Project Employees

5. R\&D project personnel

The first issue that is apparent by this research is that Nokia assumes all of their expatriates are well "trained" and well briefed on what is expected of them in their new assignment (Mendenhall, Oddou \& Stahl, p. 175). Project Managers failed to recognize many expatriates lack different levels of knowledge and motivation that the host company requires for success.

There are at least five differences and issues between the expatriate groups on assignment. The first issue deals with how goals should be set and by who. The second issue is how and who should conduct evaluations of expatriates. The third is that it was unknown if the expatriates were trained or should have the opportunity to attend any training on assignment. The fourth is that it was unknown if expatriates agreed on plans for any type of development (Mendenhall, Oddou, and Stahl, 2007).

The five issues are the main concerns for this study. Top expatriates managers face distant performance evaluations from superiors based in Finland or any other but the host country. These distant evaluations are deemed inaccurate and biased at best. Middle managers face listening challenges and take orders from superiors who are based in headquarters in Finland. Business establisher expatriates only have one directive; ie leaving Finland to the host, "Acquire new customers - Period." The Business establisher expatriates face few performance goals, which makes it impossible to measure their success on assignment. The Customer Project expatriate's assignment involves a three-phase project, which is a more intensive assignment than any of the others. Incredibly, they have no agreed performance goals and only work on expectations coming from the local Manager. Research and Development expatriates work closely with their managers and get the brunt of the work accomplished at a faster pace. However their set goals are vast and generalized, which makes it almost unquantifiable. The Training for Research and Development expatriates would never be part of any training or be offered any training while they were on assignment.

The apparent disconnect of the five groups and the Nokia Telecommunications managers are real. In order for any performance measures to happen, you must have set goals for the employees on assignment. These goals must be set in conjunction with the local country's input and expectations onsite. As of now, appraisal performance evaluations come from domestic American appraisal frameworks. However, the international assignments are one of a kind and obviously don't have the same needs of those domestic assignments (Carroll and Schneir, 1982). International companies cannot just assess any situation thousands of miles away, the same way you could if your superior were stationed locally. It is apparent that the distance and the lack of effort to set goals locally with the project manager have hurt Nokia's employees on some assignments. Nokia Telecommunications needs to find a common ground and understanding when setting goals for expatriates abroad. Constant evaluation and training is needed to build a strong team built around expatriates. The crucial part of building strong and accurate appraisals is for any evaluator to visit the local country on a constant basis to get a better grasp of the local situation (Murphy and Cleveland, 1991). Having boots on the ground would reduce or prevent inaccurate and biased evaluations as the superiors would be able set goals based on the host country's needs and not what they think five thousand miles away.

\section{ALTERNATIVE TO ENHANCE PERFORMANCE}

Cultural differences often function as barriers to progress for organizations operating in a foreign country. More than ever, these barriers are evident in emerging markets where the cultural gap between the local workers and the international managers are especially wide. In order for an organization to be successful, it becomes essential for the international managers to overcome the cultural differences and develop strategies that work for all parties 
involved. The goal for any organization working overseas is to reduce employee turnover, make workers more reliable, and develop local leadership (Litrico, 2007, p. 1).

To overcome the cultural differences, the need for talented global workers has increased. In many companies, cross-cultural training has become an integral part of staff and management training. Supporters of cross-cultural training argue that it eases the stresses of relocation, wards off culture shock and smoothes crosscultural business relations (Lang, 2004). In its pure form, Janet Bennet, executive director of the International Communication Institute (ICI) in Portland, Oregon, and one of the early pioneers of the intercultural movement says that intercultural training programs tend to teach people "the knowledge, skill and motivation to communicate effectively and appropriately in a wide variety of cultural contexts" (Lang, 2004). Although cross-cultural training has proven to be an effective method, companies are still reluctant to invest in the education of their global employees. The lack of training often results in poor performance levels and undesirable results for the company. In the case of Nokia Telecommunication, it is obvious that the lack of comprehensive and effective cross-cultural training for the expatriate managers is hurting the organization.

In order for Nokia to improve their performance, it becomes essential for the expatriate cultural training to be tailored to each country's culture and even subcultures (e.g. social vs. business). More attention has to be given not only to the design and content of the expatriate training, but also the neglected evaluation of this training and the development of interpersonal and management skills, as well as efficacy building and leadership effectiveness (Luthans, 2007). The use of a multi-source (360-degree) feedback would provide Nokia with a way to both evaluate the learning, behavioral change and performance improvement outcomes of the expatriate training. Furthermore, this would provide them a way to develop expatriates while in their assignments to make them more effective employees (Luthans, 2007).

\section{DIMENSIONS OF THE 360-DEGREE FEEDBACK SYSTEM}

Multi-source or 360-degree feedback is a process that allows managers various ratings from a variety of sources. These sources include peers, managers, direct reports, and sometimes even customers. The 360 instrument measures perceptions across six dimensions or scales: technical competence, management skills, interpersonal skills, confidence/efficacy, leadership effectiveness, and cultural fit (Luthans, 2007).

Technical competence. The expatriate's perceived technical competence from the manager, subordinates and peers (hereafter referred to as "others") would be measured by items such as "This person is able to answer my questions" and "This person is technically competent" (Luthans, 2007).

Management skills. This scale would measure the perceptions that others have of the expatriate's ability to solve specific problems and contribute to the MNC's broad goals. Also included in this scale would be the ability to plan, coordinate the work, schedule resources, try out new ideas, and control and follow-up. The focus would be on items considered as traditional management duties and skills. These would be measured by such items as "Achieves effective workflow through coordination and scheduling of resources," "Takes initiative, shows inventiveness, and is willing to try new ideas," and "Follows up and gets things done" (Luthans, 2007).

Interpersonal skills. This scale would measure the others' perception of the expatriate's capability to get along with and work through others in a caring way. Included in this would be items such as the expatriate's listening skills, giving credit and feedback to other workers, and, in general, having a caring, empathetic concern for everyone. This would include specific items, such as "Provides me with timely information and feedback," "Listens to my ideas and concerns," "Recognizes and gives credit to others who deserve it," and "Has a caring empathetic concern for others" (Luthans, 2007).

Leadership effectiveness. This scale would measure the others' view of the expatriate's desire and confidence to lead and work through people to accomplish assigned duties and would include items such as "Likes to work with and through others to accomplish assigned duties," and "Exhibits confidence in being able to lead others." The effectiveness side of this scale would ask the multi-sources to rate "Overall, this person is effective in his or her current position" and "This person is loyal and committed to this organization" (Luthans, 2007). These four scales 
are traditionally incorporated in the evaluation of managers; however, the last two scales of confidence/efficacy and cultural fit are quite unique and can have great value for an organization.

Confidencelefficacy. The measurement of this unique scale includes such items as "Puts forth considerable effort to effectively accomplish assigned duties," "Persists when encountering obstacles or problems," and "Exhibits confidence in being able to successfully accomplish assigned duties." These questions would assess not only others' perception of the global levels of the expatriate's confidence, but would also consider efficacy in the specific context of his/her specific job in the foreign culture and how much effort and persistence are exhibited. In comparing the self-ratings of confidence/efficacy with the ratings of others in the local culture, the process would be able to pinpoint discrepancies in the expatriate's self-efficacy which may call for building self-efficacy through successful experiences, modeling, and the feedback from others. Enhanced efficacy, in turn, would lead to improved expatriate performance (Luthans, 2007).

Cultural fit. The questions in this final scale need to assess the degree to which the manager is "fitting in" to the local culture. This recognizes the contingency's (if-then) nature of cultural fit for expatriate training and development discussed earlier. Questions would include such items as "I would feel comfortable inviting this person to dinner in my home" or "This person understands our customs and traditions" (Luthans, 2007).

\section{THE CONCEPTUAL FOUNDATION}

The stated alternative is for Nokia Telecommunications to use the 360-degree feedback approach that draws its conceptual roots from several different areas. One is the traditional organizational development technique of using surveys to assess employees' perceptions. These surveys measure items, such as satisfaction with management, supervisors, pay, work procedures, and formal policies of the organization. The survey information is then fed back to those who generated it, with the goal of developing an action plan to improve the organization. In the traditional organization development literature, this survey feedback technique has been well received. Another area in which 360-degree feedback has strong conceptual roots is in the performance appraisal literature. This can assist in the appraisal process for Nokia communication's expatriates. Again, today's business climate has forced organizations to provide more information than that of the traditional performance review, thus spawning such creative efforts as 360-degree feedback. It is now recognized that managers can improve their performance through increased information. Social cognitive theory (Bandura, 1986; Stajkovic and Luthans, 1998a), in particular the dimension of self-awareness, can be used to explain the benefits of such a program. This theory states that humans have the ability to assess their own capabilities and skills and that they often evaluate themselves quite differently than others do. Therefore, the 360-degree process provides managers with an external source of information designed to increase their self-awareness. This enhanced self-awareness may improve managerial effectiveness by providing individuals with another source of outside information regarding what others expect of him/her (Fletcher and Baldry, 2000). This seems particularly important in helping develop the Nokia expatriate managers who may not be clear as to what locals expect of them in their culture.

In addition to development of the instrument, the authors propose certain steps for implementation. First, every effort should be made to assure the participants of complete confidentiality. If results are to be accurate and useful, they cannot be used for other purposes besides the expatriate's own personal development. If expatriates perceive that others in the home office or at the local site will see the results and use them for evaluation or political purposes, they most likely will not give them to anyone who will give them constructive feedback or criticism. Likewise, if the collected information is perceived as having other uses, it is quite likely that those filling out the surveys would not give accurate, constructive feedback. But if anonymous, there is no reason to neither ingratiate nor degrade the expatriate. Administrators of EMEQ should completely understand and believe in the program, use an outside consultant to gather and process the data, and provide one-on-one feedback. As noted previously, this confidentiality can be especially difficult to ensure in high power distance countries, but if framed right, it can be accomplished. After confidentiality and anonymity is assured, a packet would be distributed to each Nokia expatriate. The packet should contain a cover letter detailing the purpose of the program and the directions. Also included in the packet would be several blank EMEQ surveys with six pre-addressed and stamped envelopes to send to outside consultants. The first step would be for the expatriates to fill out the EMEQ, evaluating how they perceive themselves on the dimensions outlined in the previous section. Then, the expatriate would distribute the 
remaining EMEQs to others in the organization. The expatriate may be allowed to choose who fills out the questionnaire, with emphasis on giving them to those who can provide them with the most accurate, useful information regarding the six dimensions. They should be reminded that it is of little use to give the EMEQ to those whom they already know how they will answer, either positive or negative. They should be encouraged to give it to those who can honestly and objectively assess the proposed dimensions. As the 360-degree name implies, the EMEQs are given to the boss, two or more peers, three or more direct reports and even customers, if appropriate. The outside consultant should then tabulate the surveys and the average calculated from aggregated data (not even broken down or identified by peers, manager or subordinates).

\section{THE PRESENTATION OF THE RESULTS}

In line with the personal development thrust of this program, the results should be fed back in a positive coaching format by the outside consultant. The coaching session would begin by explaining and interpreting each of the six scales that were measured. This could then be shown as a summary table, followed by a visually appealing spider diagram, which is a hexagon with a scale going out from the middle for each dimension, comparing the selfperception with the average of all of the other responses. Such a spider diagram is useful for visually pinpointing both major areas of strength and weakness as well asmajor areas of discrepancy between self and others' perceptions (Hodgetts and Luthans, 1998). Nokia's expatriates' feedback could also include a more detailed analysis of each question. This would primarily be used to provide the expatriate with specific details on what they can improve upon. Sometimes, for example, a scale like "interpersonal skills" can show a low score when really there is only one thing wrong. The expatriates need to know this in developing their own personal development action plan. The final portion of the Nokia expatriates' feedback information sheets may include any subjective reactions offered by the others. To preserve confidentiality, the outside consultant should type such comments. Although they can provide some valuable insight, the coach must caution the expatriate that although subjective comments tend to be very salient to recipients, they should not outweigh the more reliable and generalized averages from the objective EMEQ.

\section{A DEVELOPMENTAL COACHING APPROACH AND SUMMARY}

The coaching session for the Nokia expatriate should be conducted so that it turns out to be a very positive experience, regardless of the results. The emphasis in the coaching should be on strengths and improving on what the expatriate does best, not what they do worst. Focusing on improving strengths is the best way to develop the expatriate's confidence and thus performance (Buckingham and Clifton, 2001; Luthans et al, 2001). However, the identified deficiencies, especially if there is one between the self and others, can be used to assist the expatriate in developing his own personal action plan for self-improvement in technical, managerial, interpersonal, leadership, confidence/efficacy, and cultural fit. Such a development frame allows the coaching session to avoid discussing the six dimensions in terms of "weaknesses" or any other negative term. The guideline is that the coach makes sure the expatriate is aware of what others think, but focuses on his strengths (as presented in Table 2).

Nokia is on the right track by investing resources into cross-cultural training as a way to improve job performance of their international assignees. This study provided an overview of performance management using Nokia Telecommunications and identifying five main expatriate groups working abroad, including top-level management, middle management, business establishers, customer project employees, and R\&D project personnel. Although expatriate groups varied, each was established between the employee and the supervisor once the expatriate arrived in the host country. Furthermore, the 360-degree feedback technique would be an effective tool for evaluating the different levels of expatriate training. By using this technique, Nokia would be able to understand what part of their expatriate manager training programs are helping their employees and which ones need to be improved.

Questions that remain open for discussion are whether the suggested appraisal process is a good one and if the 360-degree feedback system would work for other national and multinational firms. If so, why or why not and what changes would need to be made to make it useful for global application in all firms? 
Table 2 - Elements of the 306-degree Feedback System

\begin{tabular}{|ll|ll|}
\hline 1. & Confidentiality & - & Respondent must clearly understand/believe in program \\
& & - & Use outside consultant to gather and process data \\
& & Provide one on one feedback
\end{tabular}

\section{AUTHOR INFORMATION}

Bahaudin G. Mujtaba, D.B.A., is an Associate Professor of International Management and Human Resources Management at Nova Southeastern University's H. Wayne Huizenga School of Business and Entrepreneurship. Bahaudin has served as manager, trainer and management development specialist in the corporate world as well as a director, department chair and faculty member in academia. His areas of research are management, training, diversity management, and cross-cultural management.

Hallie Fisher is currently completing her Masters of International Business Administration degree at the Nova Southeastern University's the H. Wayne Huizenga School of Business and Entrepreneurship. Her research interest includes topics in the fields of management, international business, ethics, and globalization.

Anne-Sophie Friis is the OIT computer lab specialist at Nova Southeastern University. She holds a business administration degree, and is currently pursuing her master in international business at Nova Southeastern University. She has 2 years of financial analyst experience and 2 years of sales management experience. Her areas of research include management and marketing.

Nadine Johnson is a marketing and sales professional and her area of proficiency is within the Caribbean region. She holds a degree in Professional Management, from the Nova Southeastern University in South Florida. She has experience working with 3 global multinationals, 10 years of Sales management experience, 5 years of corporate management, 6 years in Marketing and business management and 4 years Corporate business management experience within in the U.S.A.

Leah Kirkwood is currently finishing a Masters of International Business Administration degree at the Nova Southeastern University's the H. Wayne Huizenga School of Business and Entrepreneurship. Her research interests are in the areas of international business, service and globalization.

Gerardo Flores is currently completing a Masters of International Business Administration degree at the Nova Southeastern University's the H. Wayne Huizenga School of Business and Entrepreneurship. His study and research interests include leadership, management, and international business. 


\section{REFERENCES}

1. Alston, B. A. and Mujtaba, B. G. (2008). Performance Management and Execution: Strategically Providing Effective Feedback through Ongoing Appraisal Systems. Proceedings of Oxford Business and Economics Conference, ISBN: 978-0-9742114-7-3; June 22-24, 2008; Oxford, United Kingdom.

2. Aquinis, H. (2007). Performance management. Pearson Prentice Hall; Upper Saddle River, New Jersey.

3. Bandura, A. (1986), Social Foundations of Thought and Action. Prentice-Hall, Englewood Cliffs, NJ.

4. Buckingham, M., Clifton, D. (2001), Now, Discover Your Strengths. The Free Press, New York, NY.

5. Carroll and Schneir (1982), Expatriate performance appraisal in U.S. multinational firms. Extracted on May $18^{\text {th, }} 2008$ from http://www.questia.com/googleScholar. qst;jsessionid=L4JGr5f91Qp3mxSnJ0jqyVZhY41sdjLRGLMMgsZG8hx1XyJP2PPP!833583709?docId=5 $\underline{000452936}$

6. Chea, A. C. (Winter 2008). Self-management and personal leadership: why and how highly effective people succeed in achieving their goals in organizations. SAM Management In Practice, Vol 12(1), pages $1-8$.

7. Collins, A. C.; Blakeman, A.; Acuna, H.C.; Chin, J.; Cohen, S.A; and Copote, Y. (2006). How to Overcome Conflict and Maintain Their Employee Proposition at a Global Level. Paper presented at Nova Southeastern University; MIBA’s International HRM Course. November 13, 2006.

8. Grote, D. (2002). The performance appraisal question and answer book: survival guide for managers. AMACOM - New York, NY.

9. Gunn, R.W., Gullickson, B.R., (2005). Feedback: gift to the giver. Strategic Finance. 87 (2) 8-10.

10. Lang, Gretchen (2004, January 24th). International Herald Tribune. Retrieved May 8, 2008, from Crosscultural training: How much difference does it really make? Web site: http://www.iht.com/articles/2004/01/24/rcross_ed3_.php

11. Lee, C. (2006). Feedback, not appraisal. HRMagazine. 51(11) 111-115.

12. Litrico, Jean-Baptiste (2007). Beyond Paternalism: Cross-cultural. Retrieved February 12, 2008, from Journal of Business Ethics Web site: http://proquest.umi.com. ezproxyremote.library.nova.edu/pqdweb?index $=0 \&$ did $=1265259851 \&$ SrchMode $=1 \&$ sid $=1 \&$ Fmt $=6 \&$ VInst $=$ PROD \&VType $=$ PQD \&RQT $=309 \& V N a m e=P Q D \& T S=1202847068 \&$ clientId $=17038$

13. Luthans, Kyle W. (2007). Expatriate development: the use of 360-degree feedback. Retrieved May 15, 2008, from Emerald Web site: http://0-www.emeraldinsight. com.novacat.nova.edu/Insight/ViewContentServlet?Filename=Published/EmeraldFullTextArticle/Articles/ 0260211004.html

14. Luthans, Kyle W. (2007). Expatriate development: the use of 360-degree feedback. Retrieved May 20, 2008, from Emerald Web site: http://0-

www.emeraldinsight.com.novacat.nova.edu/Insight/ViewContentServlet? Filename=Published/EmeraldFullTextArticle/Articles/0260211004.html

15. McAndrews, J. (2005). Managers should apply positive and negative feedback. American Agent \& Broker. 77 (7) 16-18.

16. Mclaughlin, P. (2007). Giving good feedback. SuperVision. 68(2) 7.

17. Mendenhall, Mark E.; Oddou, Gary R.; and Stahl, Gunter K. (2007). Readings and Cases in International Human Resource Management - 4th ed. Routledge Publishers, Taylor \& Francis Books

18. Mujtaba, B. G. (2008). Coaching and Performance Management: Developing and Inspiring Leaders. ILEAD Academy Publications; Davie, Florida, USA. ISBN: 978-0-9774211-4-5.

19. Mujtaba, B. G., (2007). Mentoring diverse professionals ( $2^{\text {nd }}$ edition). ILEAD Academy, Davie, Florida.

20. Murphy and Cleveland (1991). Expatriate performance appraisal in U.S. multinational firms. Extracted on May $18^{\text {th, }} 2008$ from http://www.questia.com/googleScholar. qst;jsessionid=L4JGr5f91Qp3mxSnJ0jqyVZhY41sdjLRGLMMgsZG8hx1XyJP2PPP!833583709?docId=5 $\underline{000452936}$

21. Nokia (2008). Nokia Corporation Website (2008). Retrieved on July 21, 2008 from: http://www.nokia.com.

22. Pollitt, D. (2004). Nokia connects HR policy with company success. Human Resource Management International Digest (Vol. 12, pp. 30-32). 